\title{
Comparative Study on the Stability of SBS Modified Asphalt with M Resin Replacing Sulfur
}

Zhen Lei
School of
Transportation
and
Vehicle
Engineering
Shandong
University of
Technology
Zibo, China

Jinyi Lu
Shandong
Tongzhou
Engineering Con
sulting Co., Ltd.
Zibo Branch,
Zibo, China

Zhirong Jia*

School of Civil

and Architecture

Engineering

Shandong

University of

Technology

Zibo, China

Zhirong Jia*
School of Civil
and Architecture
Engineering
Shandong
University of
Technology
Zibo, China

Chaoyu Li

School of

Transportation

and Vehicle

Engineering

Shandong

University of

Technology

Zibo, China

\author{
Xuefeng Lin \\ School of \\ Transportation \\ and Vehicle \\ Engineering \\ Shandong \\ University of \\ Technology \\ Zibo, China
}

\begin{abstract}
In order to compare the difference between M resin and sulfur modified asphalt stabilizer, two stabilizers were prep ared according to the mass ratio of sulfur is $75 \%$, tetramethylthiuram disulfide is $20 \%$, and zinc oxide is $5 \%$. The resin is equ ivalently incorporated in such a way that the sulfur mass remains unchanged. The softening point, penetration, $5{ }^{\circ} \mathrm{C}$ ductility, and 48-hour softening point difference index of the modified asphalt were measured in five cases: $0 \%, 0.05 \%, 0.10 \%, 0.15 \%$, and $0.2 \%$. The change law of each index, and the physical dispersion state of SBS modified asphalt was compared by fluoresc ence microscope. The test results show that with the increase of the amount of the two stabilizers, the softening point of the modified asphalt increases, the penetration degree decreases, the softening point difference at 48 hours decreases, and the ducti lity at $5{ }^{\circ} \mathrm{C}$ increases first and then decreases; $\mathrm{M}$ resin-based stabilizers and The optimal blending amount of sulfur-based stabi lizers is $0.15 \%$; under the optimal blending amount, compared with sulfur-based stabilizers, the $\mathrm{M}$ resin base has a reduced so ftening point of modified asphalt of $0.6{ }^{\circ} \mathrm{C}$ and an increase in penetration index of $2.2(0.1 \mathrm{~mm})$, the ductility at $5{ }^{\circ} \mathrm{C}$ is redu ced by $0.7 \mathrm{~cm}$, and the softening point difference at $48 \mathrm{~h}$ is increased by $1.4{ }^{\circ} \mathrm{C}$. The sulfur-based stabilizer is slightly better th an the $\mathrm{M}$ resin-based stabilizer, but the difference is not large. Microscopic analysis also proves the effectiveness of the two st abilizers. It is feasible that $\mathrm{M}$ resin replaces sulfur to prepare modified asphalt stabilizer.
\end{abstract}

Key words: M resin; sulfur; SBS modified asphalt; stabilizer; thermal storage stability

\section{INTRODUCTION}

$\mathrm{M}$ resin is a by-product produced during the preparat ion of rubber accelerator $\mathrm{M}$ by a high-pressure method. $\mathrm{M}$ resin is yellow viscous at normal temperature, has no flu idity, and is a hazardous solid waste containing sulfur.

M resin is difficult to handle. Liu Anhua et al. Used $\mathrm{M}$ resin, phenol, and formaldehyde as raw materials to co polymerize them into thermoplastic resins ${ }^{[1]}$; Yin Zhigang et al. Mixed $\mathrm{M}$ resin with sulfur through high temperature and high pressure to generate accelerator $\mathrm{M}^{[2]}$. Limited $\mathrm{b}$ $\mathrm{y}$ processing cost and technology, $\mathrm{M}$ resin is often simply burned, which emits harmful gases such as sulfur dioxide, nitrogen oxides, and hydrogen sulfide, causing air pollutio n.

Modified asphalt is obtained by adding a certain amo unt of modifiers such as ethylene-butadiene-styrene block copolymer (SBS) to the matrix asphalt, and its road perfor mance is significantly improved than the matrix asphalt. $\mathrm{H}$ owever, SBS has poor compatibility with matrix asphalt a nd cannot be stably dispersed. To this end, it is necessary to incorporate sulfur-containing stabilizers to improve ther mal storage stability ${ }^{[3-4]}$. Due to the high sulfur content of $\mathrm{M}$ resin, the total content of elemental sulfur and compou nd sulfur is about $20 \%-38 \%$. Therefore, an attempt was made to replace the $\mathrm{M}$ resin equivalently with sulfur to $\mathrm{pr}$ epare a stabilizer. By comparing with the traditional stabili 
zer, the stability of the resin Effect, to explore new ways of using $\mathrm{M}$ resin waste.

\section{MATERIALS}

The A-grade 70 \# Qilu road petroleum asphalt was selected in this experiment. The basic indicators are shown in Table 1. In the test, SBS with a star and linear ratio of 1: 1 was used as the modifier. The materials used in the test met the requirements of JTGF40-2004 "Technical Specifications for Highway Asphalt Pavements".

Table 1 Asphalt technical index test results

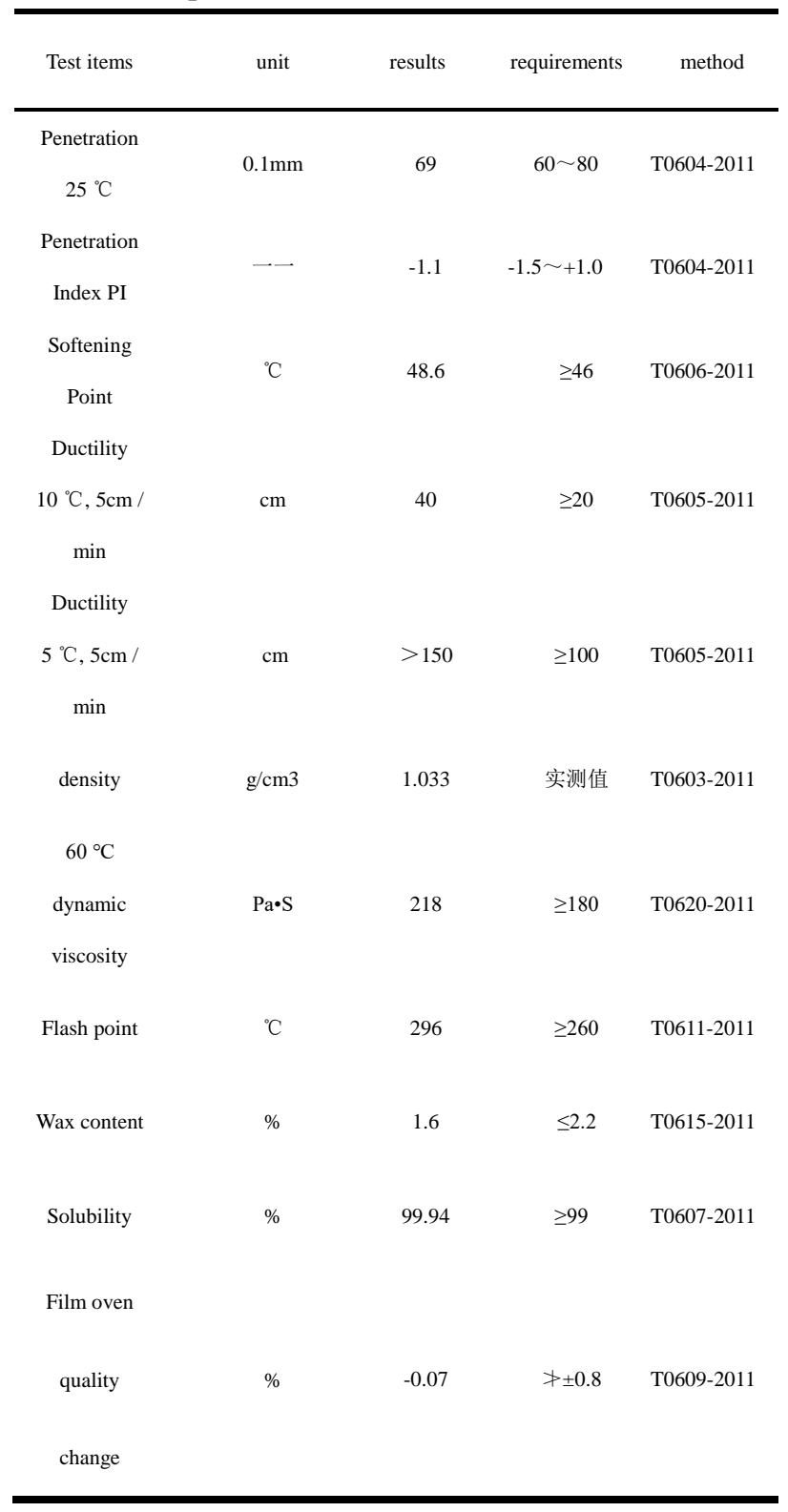

The $\mathrm{M}$ resin (A) selected for the test was provided by Shandong Shangshun Chemical Co., Ltd. as a vulcanizi ng cross-linking agent in the stabilizer; the sulfur used in the test comparison was produced by Tianjin Damao Che mical Reagent Factory with a purity higher than $99.5 \%$; $\mathrm{S}$ hanghai Dibo Tetramethylthiuram disulfide (B) produced b y Chemical Technology Co., Ltd. is used as a vulcanizatio $\mathrm{n}$ crosslinking accelerator; zinc oxide (C) produced by Yan tai Shuangshuang Chemical Co., Ltd. is used as a vulcani zation crosslinking active agent. Among them, Shandong $\mathrm{S}$ hangshun Chemical Co., Ltd. commissioned Shanghai Micr ospectrum Technology Co., Ltd. to perform in-depth micro spectral analysis on the mixture $M$ resin. The microspectra 1 analysis test results are shown in Table $2^{[5]}$.

Table $2 M$ resin microspectrum depth analysis results

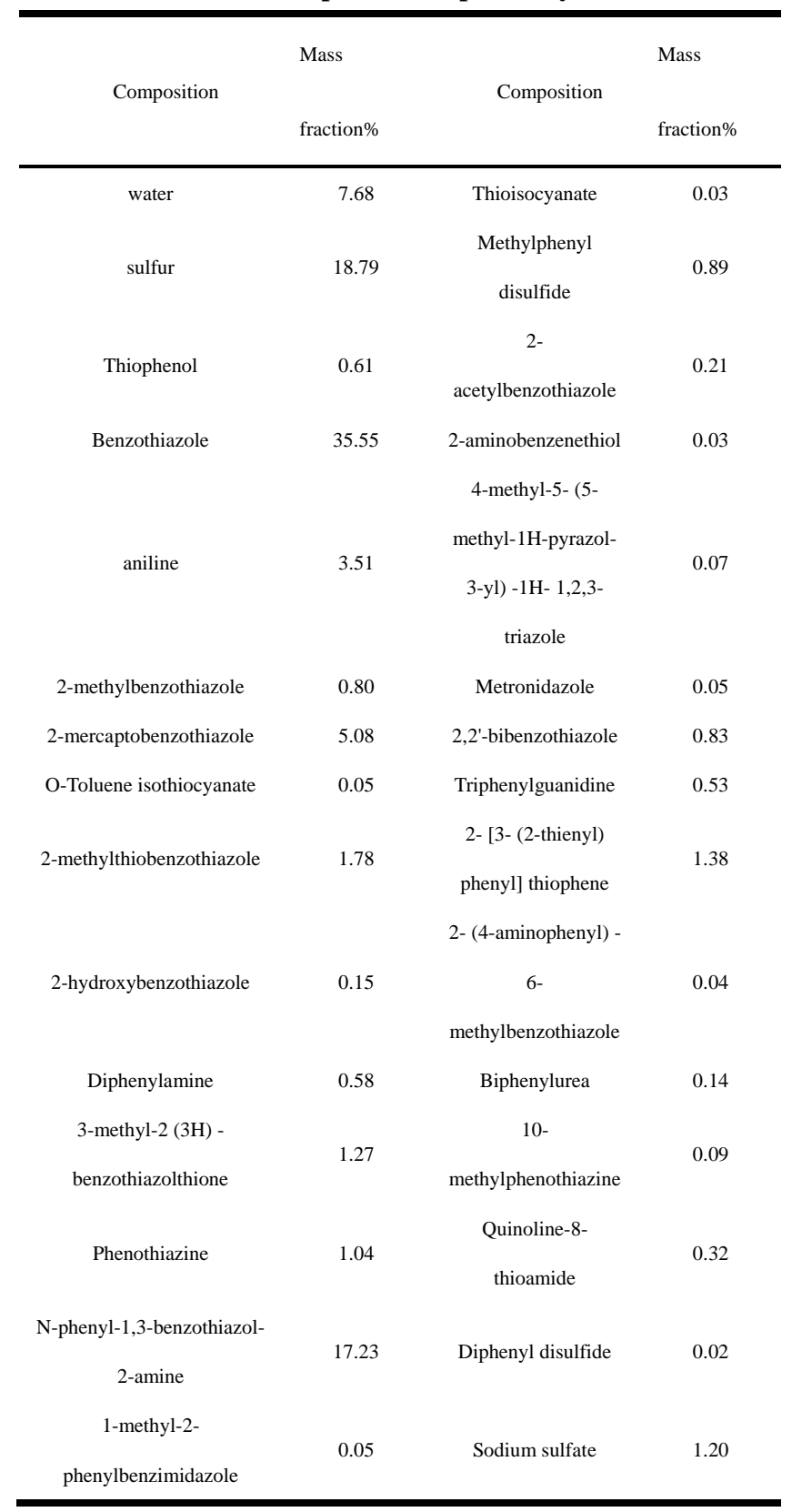

\section{EXPERIMENTAL METHOD}

\subsection{Preparation of SBS modified asphalt}

The process is as follows: (1) heating the matrix asphalt to $180^{\circ} \mathrm{C}$ and maintaining the temperature constant; (2) weighing $4 \%$ of the mass of the matrix asphalt SBS modifier (star type: linear type $=1: 1)$ and adding to Heat to the flowing matrix 
asphalt, and then use a high-speed shearer to shear the SBS modifier into the asphalt at a shear rate of $5000 \mathrm{r} / \mathrm{min}$ for 30 minutes; (3) modify the SBS after the shearing is completed. The asphalt was developed in an oven at $180^{\circ} \mathrm{C}$ for 2 hours, during which indirect stirring was performed and two base stabilizers were added.

\subsection{Experimental design to determine the effect of stabilizers}

According to the previous research, two base stabilizers were prepared according to the mixing ratio of $\mathrm{A}$ ( $\mathrm{M}$ resin (calculated as sulfur) / S): B (TMTD): $\mathrm{C}(\mathrm{ZnO})=15: 4: 1$, and two base stabilizers were prepared. SBS modified asphalt samples with the amount of $0 \%, 0.05 \%, 0.1 \%, 0.15 \%, 0.2 \%$ (modified asphalt mass fraction), and the softening point, penetration $\left(25^{\circ} \mathrm{C}\right)$, and ductility $\left(5^{\circ} \mathrm{C}\right)$ And $48 \mathrm{~h}$ softening point index.

\section{TEST RESULTS AND ANALYSIS 4.1 Analysis of conventional performance index test results of modified asphalt}

In this section, conventional performance indicators $\mathrm{s}$ uch as penetration $\left(25^{\circ} \mathrm{C}, 100 \mathrm{~g}, 5 \mathrm{~s}\right)$, softening point, an $\mathrm{d}$ ductility at $5{ }^{\circ} \mathrm{C}$ are tested and analyzed for the prepare d $\mathrm{M}$ resin-based and sulfur-based stabilizer modified aspha lt samples. The effectiveness of the $M$ resin and the effec ts of the amounts of the two base stabilizers on the softe ning point, penetration, and ductility at $5^{\circ} \mathrm{C}$ were analyz ed. The test results are shown in Figures 1-3.

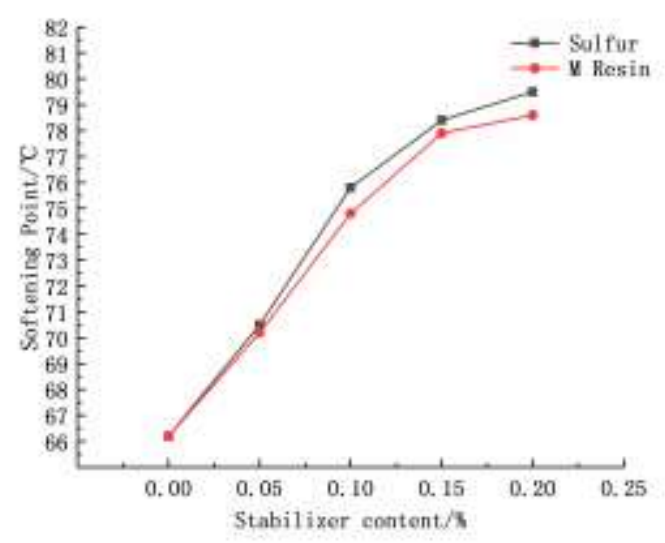

Fig.1 Softening Point Index

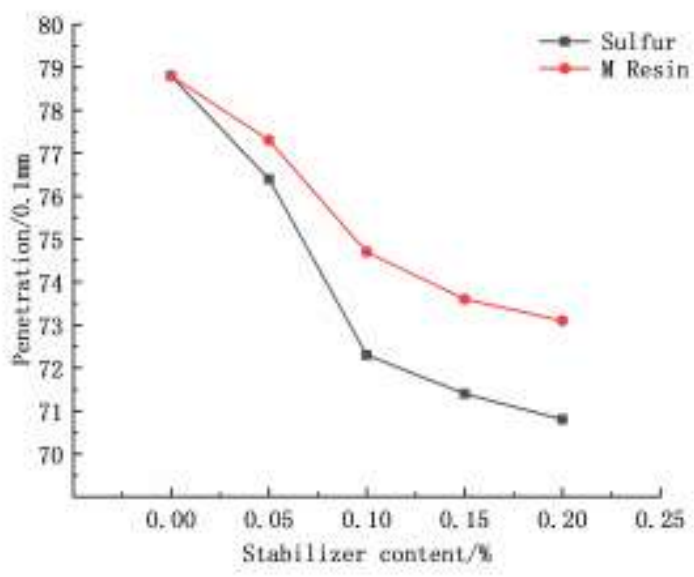

Fig.2 Penetration Index

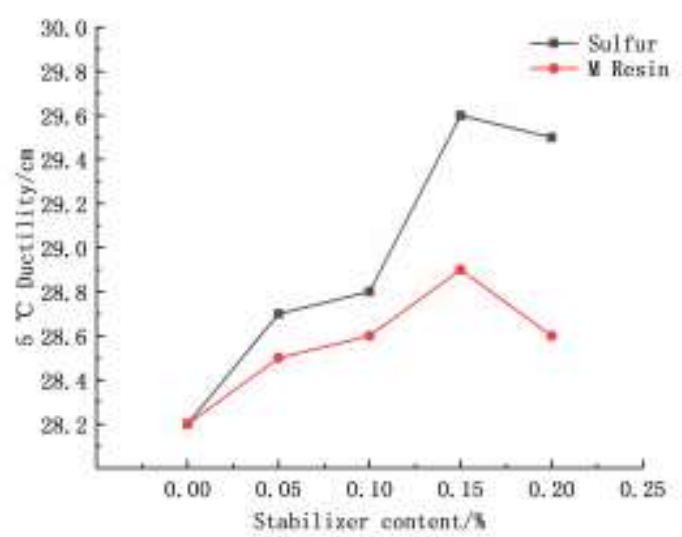

Fig.3 $5^{\circ} \mathrm{C}$ ductility index

As shown in Figure 1, with the increase in the amou nt of $\mathrm{M}$ resin-based stabilizer and sulfur-based stabilizer, $\mathrm{t}$ he softening point shows an upward trend. Although the $\mathrm{i}$ ncrease range is different, it meets the requirements of reg ularity. After adding $\mathrm{M}$ resin-based and sulfur-based stabili zers, the softening point of the modified asphalt can reach above $70{ }^{\circ} \mathrm{C}$.

As shown in Figure 2, the penetration test results of modified asphalt with $M$ resin-based and sulfur-based stabi lizers show that the penetration of modified asphalt decrea ses regularly with the increase in the amount of $\mathrm{M}$ resinbased stabilizer. It shows that with the addition of $M$ resi n-based and sulfur-based stabilizers and the increase of the amount, the viscosity of the modified asphalt material co ntinues to increase. The penetration test results ranged fro m 70 to $80(0.1 \mathrm{~mm})$. 
As shown in Figure 3, the ductility index at $5^{\circ} \mathrm{C}$ i ncreases with the increase in the amount of the two base stabilizers from $0 \%$ to $0.15 \%$. However, the modified asph alt had slight gelation and the ductility decreased when th e content of the two base stabilizers reached $0.2 \%$. The re sults of the ductility test ranged from 28 to $30 \mathrm{~cm}$.

From the comparative analysis of Figures 1 to 3 , it $\mathrm{c}$ an be seen that when the stabilizer content is increased fr om $0 \%$ to $0.05 \%$, the softening points of sulfur-based and $\mathrm{M}$ resin-based stabilizer-modified asphalt are increased by $4.3{ }^{\circ} \mathrm{C}$ and $3.9^{\circ} \mathrm{C}$, respectively, and the penetration is red uced. 2.4 and $1.5(0.1 \mathrm{~mm})$, the ductility at $5{ }^{\circ} \mathrm{C}$ increased by $0.5 \mathrm{~cm}$ and $0.3 \mathrm{~cm}$ respectively; when the blending a mount was increased from $0.05 \%$ to $0.1 \%$, the softening $\mathrm{p}$ oints of sulfur-based and $M$ resin-based stabilizer modified asphalt were increased by $5.3{ }^{\circ} \mathrm{C}$ And $4.6{ }^{\circ} \mathrm{C}$, the penetr ation decreased by 4.1 and $2.6(0.1 \mathrm{~mm})$, and the ductility at $5{ }^{\circ} \mathrm{C}$ increased by $0.1 \mathrm{~cm}$ and $0.1 \mathrm{~cm}$, respectively; wh en the blending amount was increased from $0.1 \%$ to 0.1 $5 \%$, the sulfur and $M$ resin-based stabilizers The softening point of modified asphalt was increased by $2.6{ }^{\circ} \mathrm{C}$ and 3 . $1{ }^{\circ} \mathrm{C}$, the penetration was decreased by 0.9 and $1.1(0.1 \mathrm{~m}$ $\mathrm{m})$, and the ductility at $5{ }^{\circ} \mathrm{C}$ was increased by $0.8 \mathrm{~cm}$ an d $0.3 \mathrm{~cm}$, respectively. The reason for the analysis is that the addition of sulfur-based and $M$ resin-based stabilizers $i$ mproves the high-temperature performance of modified asp halt, and the softening point and viscosity value are gradu ally increased, but excessive stabilizers are not conducive $\mathrm{t}$ o the stable diffusion of stabilizers in the asphalt and asp halt colloids. The structure is transformed into a gel type, which impairs its construction pumping ability. When the stabilizer content is too high, the low temperature crack re sistance of asphalt is damaged to a certain extent. On the other hand, the plasticity and strength of the material are two relative indicators. When a higher amount of stabilizer is added to the blending system to increase the strength, the ductility value will decrease to a certain extent. Sulfur -based stabilizers improve the high-temperature performanc e of modified asphalt better than $\mathrm{M}$ resin-based stabilizers. At the same time, the viscosity and low-temperature prop erties of modified asphalt are stronger than $\mathrm{M}$ resin-based stabilizers. $M$ resin is a mixture in which non-sulfur comp onents are mixed between sulfur and polymer to affectthe progress of its cross-linking and vulcanization reaction.

\subsection{Analysis of test results of thermal storage stability performance index of modified}

\section{asphalt}

The prepared modified asphalt samples containing $M$ resin-based and sulfur-based stabilizers were tested, and the $48 \mathrm{~h}$ softening point difference was used as an index to evaluate the thermal storage stability of the modified asphalt. The test data are shown in Tables 3, 4 and Figure 4.

Table 3 Softening point of modified asphalt with different content of $M$ resin-based stabilizer at $48 \mathrm{~h}$

\begin{tabular}{|c|c|c|c|c|}
\hline \multirow{2}{*}{$\begin{array}{c}\text { M resin-based } \\
\text { stabilizer } \\
\text { content } / \%\end{array}$} & \multicolumn{3}{|c|}{$\begin{array}{c}\text { Separation }-48 \mathrm{~h} \text { softening point } \\
\text { difference } /{ }^{\circ} \mathrm{C}\end{array}$} & \multirow[t]{2}{*}{ Note } \\
\hline & 1 & 2 & Mean & \\
\hline 0 & 35.6 & 34.0 & 34.8 & $\begin{array}{c}\text { No } \\
\text { gelation }\end{array}$ \\
\hline 0.05 & 25.8 & 26.8 & 26.3 & $\begin{array}{c}\text { No } \\
\text { gelation }\end{array}$ \\
\hline 0.1 & 13.8 & 12.4 & 13.1 & $\begin{array}{c}\text { No } \\
\text { gelation }\end{array}$ \\
\hline 0.15 & 6.7 & 5.9 & 6.3 & $\begin{array}{c}\text { No } \\
\text { gelation }\end{array}$ \\
\hline 0.2 & - & - & - & $\begin{array}{l}\text { Slight } \\
\text { gelation }\end{array}$ \\
\hline
\end{tabular}

Table 4 Softening point of modified asphalt with different content of $S$ stabilizer at $48 \mathrm{~h}$

\begin{tabular}{ccccc}
\hline $\begin{array}{c}\text { M resin-based } \\
\text { stabilizer } \\
\text { content } / \%\end{array}$ & \multicolumn{3}{c}{$\begin{array}{c}\text { Separation } \mathbf{- 4 8 h} \text { softening point } \\
\text { difference } /{ }^{\circ} \mathrm{C}\end{array}$} & Note \\
\cline { 2 - 4 } & \multicolumn{3}{c}{ Mean } & No gelation \\
\cline { 2 - 4 } 0 & 35.6 & 34.0 & 34.8 & No gelation \\
0.05 & 25.2 & 25.6 & 25.4 & No gelation \\
0.1 & 11.6 & 12.6 & 12.1 & No gelation \\
0.15 & 4.2 & 5.6 & 4.9 & Slight \\
0.2 & - & - & - & gelation \\
\hline
\end{tabular}




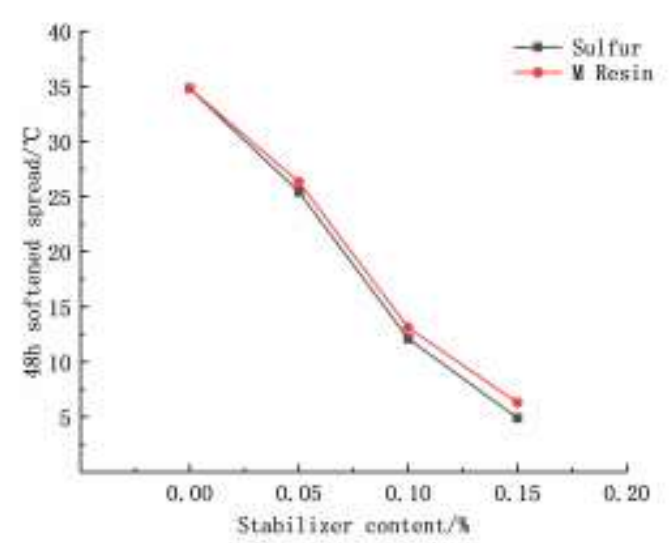

Fig.4 Index of softening spread in $48 \mathrm{~h}$

From the data in Tables 3 and 4, and Figure 4, it ca $\mathrm{n}$ be known that with the increase of the amount of $\mathrm{M}$ re sin-based and sulfur-based stabilizers, the softening point a t 48 hours gradually decreases, and its thermal storage sta bility is improved.

Tables 3 and 4 show that when the blending amount is from $0 \%$ to $0.05 \%$, the $48 \mathrm{~h}$ softening point difference o $\mathrm{f}$ the $\mathrm{M}$ resin-based stabilizer modified asphalt is reduced by $8.5{ }^{\circ} \mathrm{C}$, and the sulfur-based stabilizer modified bitume $\mathrm{n}$ is reduced by $9.4{ }^{\circ} \mathrm{C}$. When the blending amount is fro $\mathrm{m} 0.05 \%$ to $0.1 \%$, the $48 \mathrm{~h}$ softening point difference with the $\mathrm{M}$ resin-based stabilizer is reduced by $13.2^{\circ} \mathrm{C}$, and $\mathrm{t}$ he $48 \mathrm{~h}$ softening point difference with the sulfur-based sta bilizer is reduced by $13.3^{\circ} \mathrm{C}$; The $48 \mathrm{~h}$ softening point o f $\mathrm{M}$ resin-based stabilizer-modified asphalt was reduced by $6.8{ }^{\circ} \mathrm{C}$, and the $48 \mathrm{~h}$ softening point of sulfur-based stabil izer-modified asphalt was reduced by $7.2{ }^{\circ} \mathrm{C}$. With the ad dition of the same amount of stabilizer, the $\mathrm{M}$ resin-based stabilizer reduced the softening point of modified asphalt a t $48 \mathrm{~h}$ slightly less than the sulfur-based stabilizer, but the gap between the two was small. The reason for this is th at the sulfur content of the $\mathrm{M}$ resin-based stabilizer and $\mathrm{t}$ he sulfur-based stabilizer modified asphalt is the same, but because the $\mathrm{M}$ resin is a mixture, the addition of non-sul fur components may affect the sulfur modification. The di stribution in the asphalt blending system and the progress of the vulcanization reaction, the composition of the $\mathrm{M}$ re sin substance is more complicated. After researching the $\mathrm{v}$ arious components of the $\mathrm{M}$ resin, it was found that the mercaptobenzothiazole and sulfate can be used as vulcaniz ation accelerators It has a certain effect to promote the vu lcanization cross-linking reaction, which reduces the gap b etween the $M$ resin-based stabilizer and the sulfur-based st abilizer on the thermal storage stability of the modified as phalt.

\subsection{Evaluation of microstructure of modif ied asphalt}

With the help of fluorescence microscopy, the distrib ution state of the polymer and the matrix asphalt can be observed and recorded, and the homogeneity of the polym er in the asphalt can be analyzed. The prepared modified asphalt samples without stabilizers, $\mathrm{M}$ resin-based stabilizer $\mathrm{s}$, and sulfur-based stabilizers were photographed at a mag nification of 100 times under visible light using a fluoresc ence microscope, and the microscopic shapes are shown in Figures 5-7.

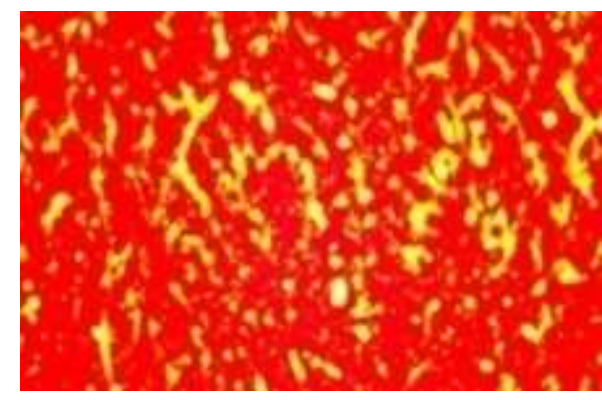

Fig.5 Microstructure of modified asphalt (without stabil izer)

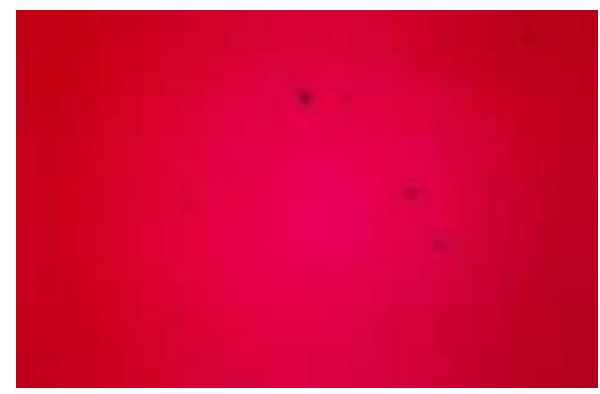

Fig.6 Microstructure of modified asphalt (M resin-bas ed stabilizer)

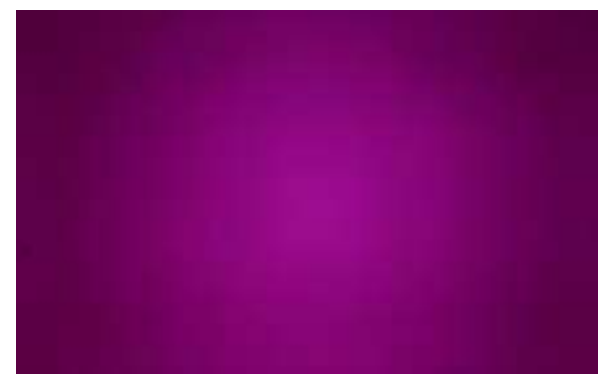

Fig.7 Microstructure of SBS modified asphalt (with S stabilizer)

From the analysis of the fluorescence photos, it can be known that the SBS modifiers are combined and aggre 
gated with each other in the matrix asphalt by a high-spe ed shearing machine at a certain temperature. There is no significant difference in the microscope images obtained $b$ $\mathrm{y}$ adding $\mathrm{M}$ resin-based stabilizers and sulfur-based stabiliz ers under fluorescent irradiation. The polymer distribution $\mathrm{i}$ $\mathrm{s}$ more uniform and better continuity than the microscopic images without stabilizers. . The reason is analyzed: the a ctive ingredient in the stabilizer improves the degree of di spersion stability of SBS in asphalt.

\section{CONCLUSION}

(1) The addition of $M$ resin-based stabilizer improve $\mathrm{s}$ the softening point and thermal storage stability of the modified asphalt, reduces the penetration, increases the vis cosity of the modified asphalt, and the ductility at $5{ }^{\circ} \mathrm{C}$ i ncreases from $0 \%$ to $0.15 \%$. During the change, it showed an upward trend, and the peak value was $0.15 \%$. When $\mathrm{t}$ he blending amount is $0.2 \%$, the ductility index at $5{ }^{\circ} \mathrm{C} \mathrm{d}$ ecreases, and the modified asphalt slightly gels, which red uces the pumping capacity.

(2) With the addition of the M resin-based stabilize $r$, SBS is uniformly distributed in the asphalt in the micro structure of the SBS modified asphalt, and the dispersion stability is improved. The SBS performance is effectively $t$ ransferred to the asphalt, the modification effect is optimiz ed, and the modified asphalt is improved. Performance.

(3) $\mathrm{M}$ resin has a higher sulfur content, and non-su lfur components such as mercaptobenzothiazole and sulfate $\mathrm{s}$ can also promote the crosslinking and vulcanization reac tion. According to the comparison of experimental data, M resin can replace the role of sulfur in stabilizers. Particip ate in the vulcanization cross-linking reaction process in $\mathrm{m}$ odified asphalt, improve the performance of modified asph alt, and the optimal blending amount of stabilizer for $\mathrm{M} \mathrm{r}$ esin basic formulation is $0.15 \%$.

\section{REFERENCES}

[1] LiuAnhua,Zhang Lili,Wen Yongxiang.Production of ac celerator $\mathrm{M}$ and utilization of waste residues[J].Rubbe r Industry, 2005,52(12): 728-730.

[2] Yin Zhigang, Chen Accompanying, Qian Hengyu.Synt hesis of Accelerator $\mathrm{M}$ and Its Application Progress [J].Synthetic Rubber Industry,2007.30 (5): 398-402.

[3] Yuan Zhongyu, Zhang Wengang, JiaZhirong, et al. F ormulation of direct injection ethylene_butadiene_omit ted_ethyleneblock copolymer modified asphalt stabiliz er based on vulcanization mechanism[J].Science Tech nology and Engineering,2018,18(13):304-309.

[4] Ouyang Yanqi, Liu Chaohui, Liu Li, et al. Study on thermalstorage stability of SBS modified asphalt proc essed on site[J].Hunan Transportation Science and $\mathrm{Te}$ chnology,2019,45(2):34-36.

[5] Shandong Shangshun Chemical Co., Ltd. M resin mi crospectrum technology report: WP-18052220-FX-01. Shanghai: Shanghai Microspectrum Technology, 2018.

[6] Giovanni Polacco,Sara Filippi.Vulcanization accelerato rs as alternative to elemental sulfur to produce storag e stable SBS modified asphalts[J].Construction and B uilding Materials, 2014,58: 94-100.

[7] Hu Kui.Quantitative technology and application of mi crostructure of SBS modified asphalt[D]. Xi'an: Chan g'an University, 2013.

[8] Xu Qi.Comparative Study on Performance of SEBS a nd SBS Modified Asphalt $[\mathrm{J}]$.Aging and Application of Synthetic Materials, 2019,48(4): 39-44.

[9] Li Jingjing, Shao Leishan, Ni Chunxia, et al. Prepara tion and thermal storage stability evaluation of coupli ng functionalized SBS modified asphalt[J].Petroleum Refining \& Chemical Industry, 2019,50(6):80-83.

[10] WangMing.Microphase analysis of SBS modified asph alt based on fluorescence microscope[J].Transportation Science and Engineering.2014,30(3):10-14.

[11] Wang Tiebao, Jia Peng, Li Yajuan.Study of the Influ ence of Stabilizers on the Performance of SBS Modi fied Asphalt[J].Petroleum Asphalt, 2008,22 (5): 6-9.

[12] Zhou Kun, Liu Xizhen, Wang Xinyang, et al.Experim ental research on storage stability of SBS modified a sphalt $[\mathrm{J}]$.Journal of Shandong Jianzhu University, 2 018,33 (4): 39-4. 